ANNE-Christine TAYLOR (D) https://orcid.org/0000-0002-8920-7440

Directrice de recherche honoraire, EREA-LESC, CNRS, Paris

\title{
Seeing, speaking and acting in Amazonian worlds. New takes on animism and perspectivism
}

W hen I was a graduate anthropology student in the 1970s in Paris, and during my formative years as a specialist in Lowland South American ethnology, we in Western Europe were aware of the significant contribution of Polish scholars (or scholars of Polish extraction) to Americanist studies; the names of specialists such as Maria Rowstorowski, Jan Szemiński, Mariusz Ziółkowski and others were familiar to us. However, the work of Polish scientists within the field of Americanism seemed to focus largely on the Andean and Mesoamerican areas, with a strong focus on ethnohistory and pre-Columbian archaeology; so far as we knew, the South American Lowlands remained outside their purview. This situation changed in the 1990's: suddenly, a trickle of Polish amazonianists, already engaged in fieldwork in various parts of the Lowlands, began appearing in the doctoral programs of French, British and American universities and more broadly at international conferences where recent trends in research were being discussed. What was striking about these young scholars was the sophistication of their approach, the breadth of their anthropological culture - they seemed to have read all the relevant literature - and their firm grasp of the theoretical issues involved in Amazonianist ethnology. In fact, in many ways they were ahead of the game: their early work immediately made strikingly original and significant additions to the emerging paradigm eventually labeled 'animism' and/or 'perspectivism'. To our (admittedly complacent) eyes, it was as if these budding specialists had just been waiting for the crystallization of this paradigm to jump in fully armed and join the international discussion it generated. I have no idea how this change of focus in Polish Americanist studies came about, how this 
nascent tradition of research was fostered, in what institutional contexts and by whom. I wish I knew more about the history of anthropology in Poland to account for it, though I imagine that the reception of Lévi-Straussian structuralism played an important part in it. What does seem clear is that the questions being explored in Amazonianist anthropology during the last decades - questions that eventually fed into the so-called 'ontological turn' - struck a chord in the Polish anthropological community.

The papers collected in this issue are evidence that this chord is still strongly resonating, and that the tradition of research initially associated with Amazonianist anthropology has taken root and prospered within the Polish academic world. Each one of these contributions has something fresh and important to say about some aspect of animism/perspectivism; taken together, they draw a useful and up-to-date panorama of the debates over animism, illuminating the complexity of the issues involved in these discussions.

But first, a brief reminder of what we are talking about. As it is used nowadays, the term 'animism' (sometimes labeled as 'the new animism', to distinguish it from its former usage based on E.B. Tylor's classic definition) refers to a feature common to many cultures across the world: the tendency to attribute personhood - modeled on humans' perception of their selfhood - to a large array of beings that we 'Moderns' would identify as natural, i.e., non-human (animals, plants, stones, artefacts...) or supernatural (gods, spirits, the dead...). In short, the categorization of things as 'persons' is much more inclusive in animist contexts than it is in our 'naturalist' world. As Descola has pointed out, any person from whatever cultural background is capable of making animist inferences on occasion: for example, when we talk to our pet, or to our computer (usually to berate it), we are behaving in animist mode. But it is only when this kind of inference is generalized and systematized to the extent that it shapes the practices and conceptualizations involved in large parts of a given cultural configuration that we can properly speak of animism. The fascination of animism lies in the fact that, if taken seriously, that is to say as a statement about the facticity of the world (rather than as a case of erroneous causal reasoning or a set of irrational beliefs, as it was in the Tylorian approach and still is in cognitivist theories of religion), it flies in the face of the entrenched division between Nature and Culture upon which the Moderns' world has come to be built; and it does so at a time when we are all becoming increasingly worried about the state of our relations to and with Nature, both as a reality and as a concept. Given this context, it is not surprising that animism has captured the Western imagination and become a focal point of anthropological theorizing. It so happens that the rise of animism as a major topic of analysis coincided with the publication of a spate of remarkably fine-grained and analytically acute ethnographies produced from the 1970's on by a new generation of Amazonianists. As a result of this coincidence, Amazonia soon came to be seen as a privileged laboratory for devising new - and generalizable - ways of accounting for animistic forms of 'worlding'. 
The picture of animism that emerged from these studies exhibits a series of interrelated features. Predation plays a salient role in it, as a general model of relations to Others and as a motor for acting in and on the world. Linked to this is a dynamic often referred to (following Erikson) as 'constitutive alterity', whereby the production of selfhood and reproduction of the social world require capturing elements from the outside world, valued by virtue of their otherness: live enemies (to be eaten or otherwise ritually slain), wives, children and pets to be adopted, trophies (shrunken or mummified heads, teeth, bones...), proper names, ritual songs or speeches, etc. Once captured through predation, such elements of alterity then undergo a process of incorporation, theorized notably by C. Fausto under the label 'familiarization', whereby they are progressively 'digested' and turned into kin, or used in one way or another to produce internal values, including life itself. This process is in turn connected to a construal of kinship as the making of congeneric bodies: humans, i.e., members of the 'species' or collective of reference, have to be made into the likeness of the bodies around them, through feeding and caring as well as through mutual speech and gaze. Failing these measures, the (potential) person may be claimed by another collective, such as the dead, or become an animal.

Perspectivism adds a further twist to this configuration. The term refers to the theorization by Eduardo Viveiros de Castro of another feature commonly found in animist configurations: the attribution to kinds of being of distinctive, non-equivalent ways of perceiving elements of reality and in particular other species. Thus, where 'we' as humans see peccaries, these same peccaries may see us in the shape of jaguars; jaguars, in turn, while they see themselves and their congeners as humans, may see ('real') humans as prey, in the shape of peccaries, and see blood as manioc beer. In other words, each set of beings will have a different perspective on the given real according to the specific nature of its body, more accurately according to the ethogram associated with a species' form of bodiliness. This is what led Viveiros de Castro to speak of 'multinaturalism' as a defining feature of animism: since each class of being sees and lives in a particular Umwelt, natures are multiple, while culture is single or homogeneous, insofar as it constitutes the unvarying bundle of capacities and dispositions inherent to the personhood of all existants occupying (at least virtually) the deictic position of 'I'. Perspective inferences may be highly generalized and systematized in some societies (such as the Juruna studied by Tânia Stolze Lima, the initial inspiration for Viveiros de Castro's theorization of perspectivism), much more limited in others (for example, restricted to interactions between the living and the dead); but it is, according to Viveiros de Castro, always present in animist configurations, if only in latent form. However, given that forms of perspectivism can also be found in cultures that cannot easily be labeled 'animist', short of voiding the concept of its classificatory value (for example, in the Mesoamerican area, as well as in Inner Asia, as Z. Szmyt's article demonstrates), and, conversely, that some clearly animistic groups exhibit no obvious traces of perspectival reasoning, 
the exact nature of the connection between perspectivism and animism - is it necessary or contingent? - is still hotly debated.

M. Żerkowski's article on Hallowell's seminal study of Ojibwe ontology provides a useful entry to the discussion of animism. While Hallowell's work is duly acknowledged as a source of inspiration for the authors involved in the study of this topic, Żerkowski rightly claims that his ideas have not received the critical attention they deserve. Żerkowski's careful contextualization and assessment of Hallowell's production brings to light the significance of his intuition that 'behind' Ojibwe ontology there lies a deeper level of cognitive operations linked to forms of perception that filter the Ojibwe's grasp on reality. He called this level the 'behavioral environment', and Żerkowski's discussion of this notion immediately makes clear its proximity to Descola's treatment of the 'ontological filters' at work in the four modes of identification he distinguishes. The two anthropologists both postulate the existence of a framework that mediates relations to the phenomenal world and that lies upriver from the cosmologies or 'ontologies' of a given collective. The difference between the two models is that, while Hallowell's culturalist grounding kept him from formalizing his notion of the 'behavioral environment' and deploying it for comparative purposes, Descola used the structuralist tool-box to turn it into a 'structure', as such endowed with comparative potential and generalizable features.

A. Pisarek's article provides a lucid overview of the debates on this matter and more generally on the central issues involved in the discussion of animism. Focusing on the way three major figures of americanist anthropology - Viveiros de Castro, Descola and T. Turner - deal with Amazonians' 'confusion' of nature and culture and their idiosyncratic view of humanity as a deictic position, he carefully pinpoints the areas of convergence and dissension between the models developed by these three authors, all rooted in Lévi-Straussian structuralism (strongly inflected by Marxism, in Turner's case). He shows how Viveiros de Castro explodes our naturalist constitution simply by inverting the valence of the terms set up in the central opposition between Nature and Culture, and then by methodically exploring the consequences and implications of this reversal. In so doing, he elaborates what amounts to a metaphysics of the Amazonian world, albeit an ethnographically highly informed one. Descola, for his part, relativizes both our naturalism and Amazonian animism by replacing them within a broader framework including two other modes of identification, respectively called totemism and analogism, each one of these modes conceived as transformations (in the structuralist sense) of each other. It is worthwhile noting that Descola's fourfold scheme is not in any sense a typology of past and present social configurations ; indeed, he is at pains to point out that no real 'society' strictly corresponds to his categories, and that actual cultural configurations are usually hybrid, 'animist' in some fields, 'analogist' or 'totemist' in others. In classic structuralist fashion, his models referring to forms of identification are purely heuristic devices aimed at elucidating the underlying logic at work in the 'ontologies' of this or that group, and his general fourfold classification must itself be seen 
as a model of these models. Though also inspired by Lévi-Strauss's thought, Turner's approach is quite different (and more Aristotelian than Kantian): in his view, Amazonian cosmologies (and more specifically that of the Kayapo) are a reflexive take on an evolving lived world in which all beings join in, each one engaged in the process of transforming nature and capable of some order of reflexivity, so that humans' actions and reflexivity replicate at a different scale a property common to all living things. In short, culture is essentially a 'supernature'. At the end of his paper, Pisarek comes out in favor of Turner's theorization, on the grounds that it has a greater capacity to deal with ongoing change and a greater potential for 'decolonizing' anthropology, whereas both Viveiros de Castro and Descola's models are too static and remain too closely bound to Western forms of categorization. To which the latter authors might well respond that Turner's perspective is both markedly anthropocentric and reliant on a typically Western construal of history, therefore itself characteristically 'naturalist'... In any case, Pisarek's acute, well informed contribution will give the reader a valuable insight into the complexities of the issues involved in the discussions over Amazonian animism and the best ways of making sense of it.

The preceding comments may have given readers the impression that Amerindian perspectivism is a highly cerebral affair, a formalized explicitation of indigenous metaphysics that come to the fore primarily in ritual contexts, or else through the objectivation emerging from conversations with the ethnographer about the meaning of mythical narratives and ritual performances. The importance of F. Rogalski's article is to show how perspectivism actually works at the ground level, by giving a particular 'spin' to ordinary, routine behaviour. With characteristic ethnographic flair, he describes how the Arabela playfully enact and verbally label minor behavioral quirks observed in other persons: thus, a man will say 'I'm doing Nuria' when putting on oversized boots, in reference to a young girl named Nuria wearing too large boots on a previous occasion; or ' $\mathrm{X}$ is doing so-and-so', when referring to the way a person wears a cap, eats or talks in a certain way. This joking behaviour is constant among the Arabela, prompting the ethnographer to analyze in careful detail its linguistic and pragmatic dimensions, as well as the fields of practice most often selected as sources for the behaviour being indexed by this form of parody. He goes on to show how it illustrates culturally honed attention to the distinctive 'ethogram' of other subjects: persons are singularized not by their 'psychological' or personality traits but rather by virtue of the aptitudes and dispositions determined by the kind of bodies they inhabit. Further, by enacting such 'etho-traits' the Arabela are constantly engaged in 'familiarizing' and ultimately incorporating elements of alterity to produce their selfhood as well as the collective they belong to. P. Chyc's paper on the Bolivian Moré offers another valuable illustration of the 'groundedness' of perspectivism in the everyday life of an animistic society, by focusing on the stories Amazonian people commonly tell each other about odd encounters experienced while going about their ordinary tasks, such as hunting, visiting or traveling. Typically, the reported event occurs while the story's protagonist 
is alone and comes upon a being whose strangeness is indexed by an anomaly in the pragmatics of the encounter: it is seen but not heard (or vice-versa), or it behaves in an unexpected way (a deer or a peccary standing still and staring at the hunter instead of fleeing). Such creatures are said by the Moré to be 'of the other side'. Chyc goes on to analyze the properties of the 'other side', stressing its sameness to the normally perceived world while highlighting the entirely different perspective on it experienced by those who inhabit it permanently or accidentally. Given the specular relation between the two realities, he rightly points out that boundaries between this side and the 'other side' - limits such as skin and bark, the surface of water, the fringe of forest around a clearing... - play a vital but understudied role in the deployment of a perspectivist world, and he argues for the relevance of topology as a heuristic tool for illuminating the recursive, endlessly reversible contrast of visible appearance and invisible 'interiority' that plays such a pivotal role in animism. A. Przytomska-La Civita, for her part, takes up the thread of predation as it is conceptualized among the Andean Q'eros of south-central Peru. She demonstrates how in this cultural context predation becomes either a kind of forced reciprocity, when people transgress (through neglect or by committing incest) their obligation to constantly engage in the web of reciprocal exchange (ayni) that holds the world's beings together, or else a unilateral (i.e., non-reversible) aggression and subtraction of the substances that should flow between all the 'persons' that make up the Andean universe. Her contribution helps to show how the notion of predation is inflected by its embeddedness in an 'analogist' cosmos such as that of the Q'eros: while in Amazonia predation is the basic, unmarked form of relating to Others and reciprocity only obtains between congeners or persons assimilated to close kin, in the Andes reciprocity is the governing principle and predation only comes in when reciprocity, the matrix of relations between all beings including non-humans, breaks down and must be substituted by negatively valued forms of mutual sustainment.

S. Pietrowiak and Z. Szmyt's contributions deal with Inner Asian cultures and show how the conceptual apparatus elaborated to account for the dynamics of Amazonian sociality can be used to illuminate processes at work in these quite different ethnographic contexts. In this respect they follow a trend that is equally visible in Western European anthropology: while a few decades back Melanesia was the 'significant other' of Amazonia in comparative terms, to the extent that specialists of these areas jointly produced an imaginary theoretical continent dubbed 'Melazonia', this role has shifted to Inner and North Asia, and contemporary specialists of this part of the world commonly draw on Amazonianist literature to make sense of their ethnographic material. The fact that shamanic practices play a salient role in both regions provided an obvious common ground for comparative exercises, but now the use of Amazonianist concepts by Inner Asia scholars extends well beyond the domain of shamanism. Thus, Pietrowiak relies on Fausto's work on familiarization to illuminate the practice of bride kidnapping in north-eastern Kyrgyzstan and the transformation of women that it brings about, a trajectory of change that resonates with the process of incorporating pets 
in Amazonia. By detailing the major role played by the female affines of the groom and bride in the performance of marriage, she shows how women move in their life course from the position of insider as infertile child to that of captured, fertile outsider in her husband's family and then on to the respected position of 'tamer' of other captured brides; interestingly, she notes that the offspring of the two sets of female 'tamers' involved in a marriage by kidnapping are in the position of potential spouses for each other. Szmyt, by contrast, focuses on relations between the living and the dead, in the wake of the post-communist resurgence of 'necropersons' as active presences. The three fascinating cases he discusses show how these non-(live)humans come into being and are called on to intervene in contemporary life, as major actors in the production of new historical narratives sustaining the re-emergence of previously suppressed or 'invisibilized' identities. Though Szmyt does not explicitly relate his findings to Amazonian models and to the discussion of animism or perspectivism, his analysis does connect strongly with Amazonianist analyses of the relations with the dead, the politics of memory and the regimes of historicity characteristic of indigenous Lowland groups. His paper thus sets up a particularly rich ground for further comparative work on the Amazonia-Inner Asia axis.

At a time when the Polish academic world is facing a fraught situation, and when anthropology departments in particular are struggling to maintain their integrity, it is to be hoped that the quality of these contributions, beyond illustrating a thriving local tradition of Americanist-inspired studies, will help draw attention to the signal contribution of Polish scholars to the discipline of anthropology at its cutting edge, and contribute to the preservation of the intellectual and institutional environment in which their work emerged and flourished. 